\begin{tabular}{|l|l|l|}
\hline \multicolumn{2}{|c|}{ PublisherInfo } \\
\hline \hline PublisherName & $:$ & BioMed Central \\
\hline \hline PublisherLocation & $:$ & London \\
\hline \hline PublisherImprintName & $:$ & BioMed Central \\
\hline \hline
\end{tabular}

\title{
Inhibition of inflammatory arthritis by SOCS3/CIS3
}

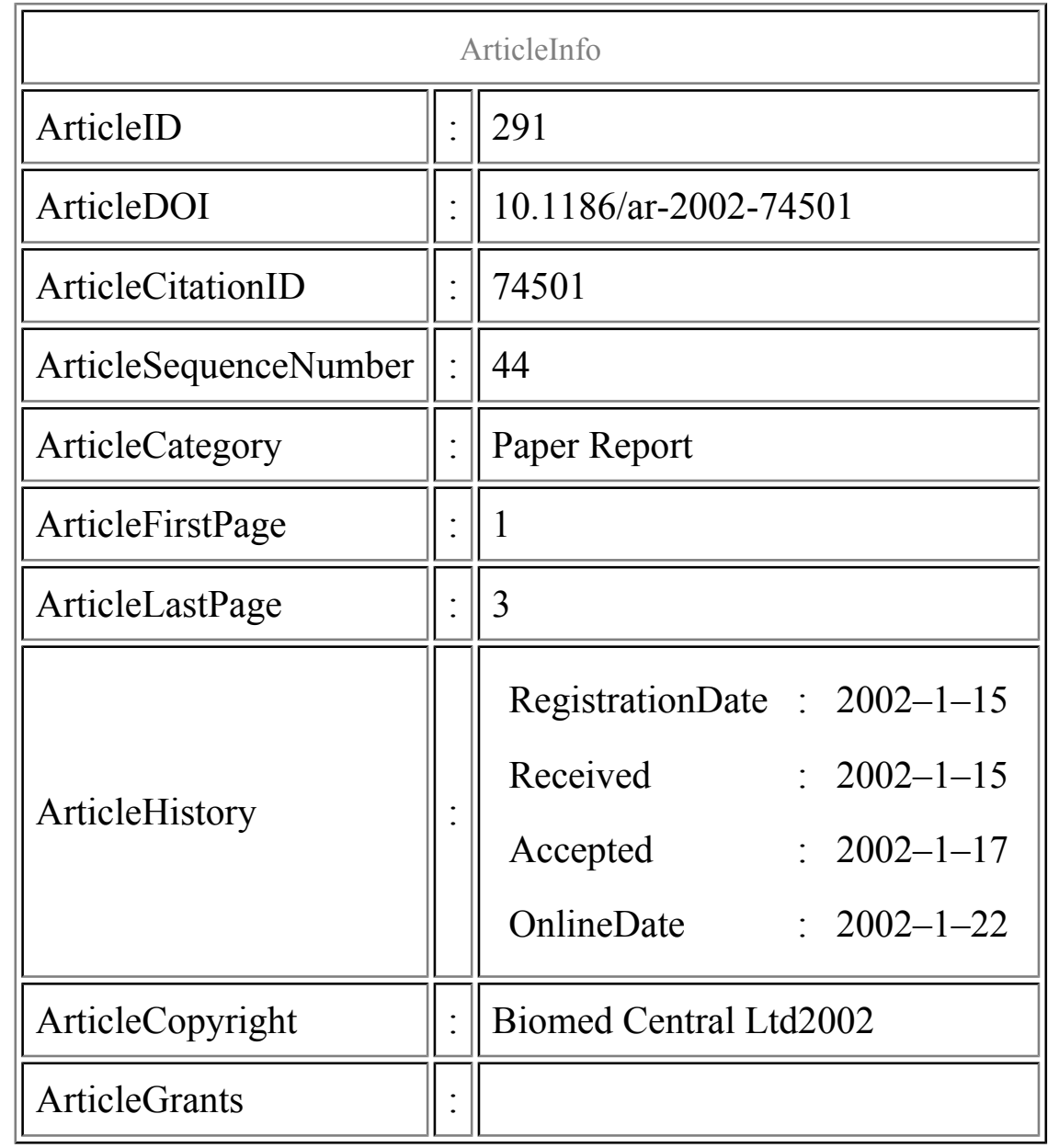




\begin{tabular}{|l|l|l|}
\hline ArticleContext & $:$ & 130754411 \\
\hline
\end{tabular}

Cheryl Smythe, ${ }^{\text {Aff1 }}$

Aff1 Imperial College Faculty of Medicine, London, UK

\section{Keywords}

adnenoviral gene transfer, anti-inflammatory, arthritis, CIS3, IL-6, STAT3

\section{Context}

The observations that IL-6 deficient mice are resistant to rheumatoid arthritis (RA) and anti-IL-6 receptor antibodies are an effective treatment for RA, have led to the conclusion that IL-6 is important in the development of disease. JAK tyrosine kinases and the STAT3 transcription factor are preferentially activated by IL-6, and STAT3 activation has been observed in RA synovium. CIS3 was recently identified as a negative regulator of the proinflammatory response and has been shown to inhibit STAT3 activation. Therefore, the authors have investigated the therapeutic potential of adenovirus-delivered dominant negative (dn) STAT3 and CIS3 in both antigen- and collagen-induced models of arthritis (AIA and CIA).

\section{Significant findings}

STAT3 activation and CIS3 mRNA expression were observed in the synovial tissues from RA patients, but not from those with osteoarthritis, suggesting a role for these mediators in inflammatory arthritis. STAT3 activation coincided with severe joint inflammation in the CIA model, while CIS3 mRNA expression occurred 10 days later by which time STAT3 activation had decreased. Therefore, CIS3 might feed back to negatively regulate STAT3 activation. Overexpression of CIS3 or dnSTAT3, following adenoviral gene transfer prior to disease onset, strongly suppressed proliferation of isolated RA synovial fibroblasts and inhibited TNFa- or serum-induced IL-6 secretion. Periarticular gene transfer of CIS3 or dnSTAT3 to the ankle joints of AIA mice resulted in the inhibition of cartilage destruction, mononuclear cell infiltration and pannus formation compared to control treated joints, and resulted in the inhibition of both STAT3 activation and IL-6 expression. In the CIA model, CIS3 gene transfer prior to disease onset significantly reduced disease severity and paw thickness. dnSTAT3 expression gave similar results, but was less effective that CIS3. Furthermore CIS3 was also effective at preventing the progression of established disease. 


\section{Comments}

This study identifies a new therapeutic strategy for RA by blocking cytokine signalling pathways. However there are problems associated with adenoviral gene transfer, such as transient gene expression and inflammation following local injection. This issue is addressed by the authors who suggest that other agents, such as JAK inhibitors or those that could stabilize CIS3 expression, may be more useful therapeutically. It would have been interesting to measure CIS3 protein levels in RA synoviocytes; although CIS3 mRNA is expressed in abundance, this does not result in the inhibition of STAT3 activation. This finding suggests that there are not correspondingly high levels of active CIS3 protein; therefore agents that promote CIS3 protein expression may be effective at inhibiting inflammatory disease.

\section{Methods}

Synoviocyte isolation, recombinant adenoviral gene transfer, ELISA, antigen- and collagen-induced models of arthritis, immunohistochemistry, immunoblot, northern and RT-PCR analyses

\section{Additional information}

\section{References}

1. Shouda T, Yoshida T, Hanada T, Wakioka T, Oishi M, Miyoshi K, Komiya S, Kosai K, Hanakawa Y, Hashimoto K, Nagata K, Yoshimura A: Induction of the cytokine signal regulator SOCS3/CIS3 as a therapeutic strategy for treating inflammatory arthritis. J Clin Invest. 2001, 108: 1781-1788.

This PDF file was created after publication. 